Brit. J. industr. Med., 1963, 20, 199.

\title{
A CAUSE OF CHROMATE DERMATITIS AMONG ASSEMBLERS IN AN AUTOMOBILE FACTORY
}

\author{
BY \\ MURIEL L. NEWHOUSE* \\ From the London School of Hygiene and Tropical Medicine and the Institute of \\ Dermatology, London University
}

(RECEIVED FOR PUBLICATION NOVEMBER 22, 1962)

\begin{abstract}
A series of 230 patients with skin disease and 66 men with no skin disease were tested with a battery of nine common sensitizing substances. Among the patients the incidence of positive reactions was $36 \%$, whereas in the control series it was $7.6 \%$. The most common sensitizing agent was potassium dichromate. The incidence of chromate sensitivity was four times greater among assemblers than among men in other jobs. Hexavalent chromate was found on the surface of the nuts, bolts, screws, and washers used by the assemblers. The source of the chromate was a chromate dip which is used as a passivator in chromium plating and zinc coating.

The process was modified in one department and the chromate dip omitted. Patch testing of 12 men who had developed dermatitis since the modification of the process revealed no further cases of chromate sensitivity. This cause of allergic dermatitis appears to have been eliminated from this department.
\end{abstract}

The exact diagnosis of industrial dermatitis remains a problem that exercises the most experienced dermatologists. Knowledge of the patient's work and the hazards it entails combined with a knowledge of his home life and hobbies is often not sufficient to enable one to differentiate between a constitutional eczema and an eczematous condition caused by injurious substances encountered at work. In such cases patch testing with a standard series of the more common sensitizing agents helps to discover the causative factor. This technique, when applied to an industrial population, may reveal a particular hazard. Pirilä (1947), in his study of the Finnish paint industry, showed that the majority of his patients with allergic dermatitis had become sensitized to turpentine.

Throughout this paper the terms eczema and dermatitis are used. "Eczema" indicates a papular vesicular rash thought to be of constitutional origin and not connected with occupation. Atopic eczema, discoid eczema, Besnier's prurigo, cheiropompholyx, and seborrhoeic eczema are included in this classification. The term "dermatitis" implies a papular vesicular rash due to an external influence, probably

*Supported by a grant from the Medical Research Council occupational in origin. The patients showing a positive patch test are classified as having an "allergic dermatitis".

As part of an epidemiological study of skin disease in a large automobile factory a series of the workers have been patch tested with nine common sensitizing substances, namely turpentine, nickel sulphate, formaldehyde, potassium dichromate, colophony resin, balsam of Peru, paraphenylene diamine, and two rubber additives, mercaptobenzthiazole and tetramethylthiouram disulphide (MBT and MS) (Table 1). In all, 230 patients with skin disease and a control series of 66 men with no skin disease and no history of dermatitis or eczema were examined.

TABLE 1

SUBSTANCES USED FOR PATCH TESTING

\begin{tabular}{l|c|l}
\hline Reagent & $\begin{array}{c}\text { Concentration } \\
(\%)\end{array}$ & Vehicle \\
\hline Turpentine & 25 & Oil \\
Nickel sulphate & $2 \cdot 5$ & Water \\
Formaldehyde & $2 \cdot 0$ & Water \\
Potassium dichromate & $0 \cdot 5$ & Water \\
Balsam of Peru & $2 \cdot 0$ & Vaseline \\
Colophony & 50 & Vaseline \\
Mercaptobenzthiazole (MBT) & 1.0 & Vaseline \\
Tetramethylthiouram disulphide & 1.0 & Vaseline \\
$\quad$ (MS) & & \\
\hline
\end{tabular}




\section{Methods}

The test substance was placed on a piece of lint one inch square folded to make a triangle. This was secured by adhesive plaster. The patches were placed in two rows across the back. The patients were asked not to bath or shower until the patches were removed 48 hours later. The results were read at 48 and 96 hours. A reaction which gave a raised red area the size of the patch and covered with fine vesicles appearing at either 48 or 96 hours was counted as positive. Other types of reaction were read as negative.

Many of the men complained of irritation from the plasters, but co-operation was very good. Only seven patients refused, in all but one of whom the original rash had nearly healed. As they were reluctant to undergo the tests they were not pressed. The seventh, a man with severe flexural eczema, was attending a herbalist. He thought the patches might interfere with his treatment. In three patients a positive reaction produced a patch of weeping eczema that necessitated daily dressings for a few days. In one man only was there a serious flare up with a generalized reaction over the face, neck, and trunk. Fortunately this responded rapidly to a short course of steroids by mouth and he lost no time from work.

\section{Population Studied}

The patients were drawn from three parts of the factory: the chassis group, the main assembly group, and the engine assembly department.

The chassis group, which employs about 12,000 men, comprises a foundry, machine shops, and assembly departments where car and tractor engines, axles, and transmission gears are built up and tractors assembled. The patients with eczema or dermatitis were selected from a group of $\mathbf{4 2 5}$ men who had reported a skin disease to the medical department and had first been examined by the author two years previously. Only the patients with at least moderately severe disease at the time of the original interview were recalled (Table 2, chassis group).

The main assembly building is a separate establishment employing about 6,000 men. Here the car bodies pass through the spray booths to be painted and are lowered to the ground floor, where the body and the chassis are assembled. The car moves forward on conveyor belts while the electrical work is done, and the windows, seats, cushions, carpets, wheels and all other accessories are fixed in position. The finished car is driven off the end of the line. The aim was to interview and test all men who attended the medical department in this building com- plaining of a skin rash during the 13 weeks between March 1 and May 23, 1962. The only skin patients excluded were those who had contracted dermatitis in a severe outbreak in the paint shop, and who had already been extensively studied (Calnan and Engel, 1963). Of the available patients, $95 \%$ were tested (Table 2 , assembly group).

The engine assembly department is where the car engines and the gear box and clutch are assembled. It is known to have a high incidence of skin disease and is at present under special surveillance. A survey of the 450 men in the department had been made in April, 1962; all men diagnosed at that time as having dermatitis, together with a few patients referred by the medical officer in charge of the department, were re-interviewed and tested (Table 2, engine assembly department).

The men who were attending the physiotherapy department during the period of the investigation formed the control series. Fifty-two came from this source; they were working in the same departments as the men in the chassis group, but, as there was only one assembler among them, another 14 men, picked at random from the files of the assembly departments, were examined. In all, 230 patients and a control series of 66 men were tested.

\section{Results}

Among the patients $36 \%$ were positive to one or more of the reagents (Table 3). Although the three groups of patients forming the series were differently selected, the proportion of sensitized patients did not vary greatly. It was $34 \%$ in the chassis group, $40 \%$ in the assembly group, and $30 \%$ in the engine assembly department series. Among the control group, there were five men $(7.6 \%)$ who showed positive reactions. Two of these were positive to paraphenylene diamine, one to turpentine, one to a rubber additive, and one to potassium dichromate. Seventy of the 82 sensitized patients reacted to one of the test substances, and 12 to more than one. The results of the patch testing are summarized in Table 4. The most striking finding was the high incidence of sensitivity to potassium dichromate. There were 48 men who reacted alone to dichromate, and eight who reacted to dichromate and one or more of the other reagents.

Twenty-six men were sensitized to reagents other than dichromate, 22 to one of the test substances, and

TABLE 2

PLACE OF WORK AND PROPORTION OF SELECTED POPULATIONS PATCH TESTED

\begin{tabular}{l|c|c|c|c}
\hline \multicolumn{1}{c|}{ Place of Work } & $\begin{array}{c}\text { No. of Patients } \\
\text { Available }\end{array}$ & $\begin{array}{c}\text { Employment Terminated } \\
\text { or Transfer }\end{array}$ & Refusals & $\begin{array}{c}\text { No. of Men } \\
\text { Tested }\end{array}$ \\
\hline Chassis group & 128 & 30 & 5 & $93(73 \%)$ \\
Assembly group & 93 & 3 & 2 & $87(95 \%)$ \\
Engine assembly department & 51 & 1 & - & $50(98 \%)$ \\
Control series (chassis group) & 75 & 9 & 7 & $66(89 \%)$ \\
\hline Total & 347 & 43 & $296(85 \%)$ \\
\hline
\end{tabular}


TABLE 3

POSITIVE PATCH TESTS IN PATIENTS FROM THREE DIFFERENT PARTS OF THE FACTORY AND IN CONTROL SERIES

\begin{tabular}{|c|c|c|c|c|}
\hline \multirow{2}{*}{ Place of Work } & \multirow{2}{*}{ No. of Men Examined } & \multicolumn{2}{|c|}{ No. of Patients Positive to: } & \multirow{2}{*}{$\begin{array}{l}\text { Total No. with } \\
\text { Positive Reactions }\end{array}$} \\
\hline & & Potassium Dichromate & Other Reagents & \\
\hline $\begin{array}{l}\text { Chassis group } \\
\text { Assembly group } \\
\text { Engine assembly department }\end{array}$ & $\begin{array}{l}93 \\
87 \\
50\end{array}$ & $\begin{array}{l}19(20.4 \%) \\
25(28.7 \%) \\
12(24.0 \%)\end{array}$ & $\begin{array}{c}13(14.0 \%) \\
10(11.4 \%) \\
3(6.0 \%)\end{array}$ & $\begin{array}{l}32(34.4 \%) \\
35(40.2 \%) \\
15(30.0 \%)\end{array}$ \\
\hline Total patients & 230 & $56(24 \cdot 3 \%)$ & $26(11 \cdot 3 \%)$ & $82(35 \cdot 7 \%)$ \\
\hline Control series (chassis group) & 66 & $1(0 \cdot 15 \%)$ & $4(6.0 \%)$ & $5(7 \cdot 6 \%)$ \\
\hline
\end{tabular}

TABLE 4

POSITIVE REACTIONS TO PATCH TESTS IN 230 PATIENTS

\begin{tabular}{|c|c|c|c|c|c|c|c|c|c|c|}
\hline & 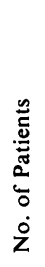 & 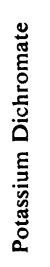 & 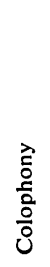 & 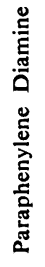 & 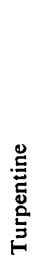 & 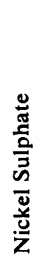 & 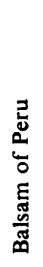 & 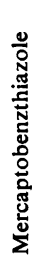 & 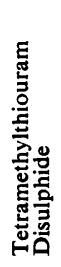 & 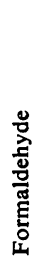 \\
\hline $\begin{array}{l}\text { Single reactions } \\
\text { Two or more reactions }\end{array}$ & $\begin{array}{l}70 \\
12\end{array}$ & $\begin{array}{r}48 \\
8\end{array}$ & $\begin{array}{l}8 \\
6\end{array}$ & $\begin{array}{l}4 \\
5\end{array}$ & $\begin{array}{l}4 \\
3\end{array}$ & 2 & $\begin{array}{l}3 \\
1\end{array}$ & $\begin{array}{l}1 \\
3\end{array}$ & $\overline{2}$ & 二 \\
\hline Total & 82 & 56 & 14 & 9 & 7 & 4 & 4 & 4 & 2 & - \\
\hline
\end{tabular}

TABLE 5

CLINICAL DIAGNOSES OF PATIENTS WITH NEGATIVE PATCH TESTS

\begin{tabular}{|c|c|c|c|c|}
\hline Place of Work & $\begin{array}{c}\text { Primary Irritant } \\
\text { Dermatitis }\end{array}$ & Eczema & $\begin{array}{c}\text { Miscellaneous Skin } \\
\text { Diseases }\end{array}$ & Total \\
\hline $\begin{array}{l}\text { Chassis group } \\
\text { Assembly group } \\
\text { Engine assembly department }\end{array}$ & $\begin{array}{l}32(52 \cdot 4 \%) \\
34(65 \cdot 3 \%) \\
26(74.2 \%)\end{array}$ & $\begin{array}{r}24(39.3 \%) \\
13(25.0 \%) \\
4(11.4 \%)\end{array}$ & $\begin{array}{l}5(8 \cdot 1 \%) \\
5(9 \cdot 6 \%) \\
5(14 \cdot 3 \%)\end{array}$ & $\begin{array}{l}61(100 \%) \\
52(100 \%) \\
35(100 \%)\end{array}$ \\
\hline Total & $92(62 \cdot 1 \%)$ & $41(27 \cdot 4 \%)$ & $15(10 \cdot 1 \%)$ & $148(100 \%)$ \\
\hline
\end{tabular}

four to more than one of them. In this group the most frequent finding was a sensitivity to colophony; eight patients gave a positive reaction to this resin alone, in six others it was found in association with other positive tests.

There were four patients whose patch test to paraphenylene diamine was positive; in five others a positive reaction was associated with sensitivity to other substances. Each of the other reagents, except formaldehyde, caused a few positive reactions.

The clinical classification of the 148 patients with negative patch tests is shown in Table 5. Of these $62 \%$ were suffering from "dermatitis". Primary irritants were the cause in most cases, but allergic dermatitis due to substances not included among the test substances may have occurred. Twenty-seven per cent were suffering from non-occupational eczemas.

Among the miscellaneous group of skin diseases there were six men with a rash on the hands prob- ably due to a dermatophytid reaction. Three of these were positive to fungus on laboratory examination; the other three were not examined for fungus, but all showed a similar clinical appearance, with maceration and cracking between the toes, sometimes with a vesicular rash spreading to the soles of the feet. All six men improved with specific treatment for fungous infections. There were three patients with psoriasis. Two of these had pustular psoriasis of the palms, which had caused some difficulty in diagnosis. Another had psoriasis with a few psoriatic plaques on the dorsum of the hands which had been erroneously diagnosed as contact dermatitis. There were also three cases of oil folliculitis, one of urticaria, and one of lupus erythematosus.

Careful details of each man's occupation were obtained at the time of the medical interview. Patients came from all sections of the factory studied, but the majority were assemblers, numbering 130 men; the number from other jobs was small. 
TABLE 6

HIGH INCIDENCE OF SENSITIVITY TO POTASSIUM DICHROMATE IN ASSEMBLERS

\begin{tabular}{l|c|c|c|c}
\hline & \multirow{2}{*}{ Total No. of Patients } & \multicolumn{2}{|c|}{ Patch Test Positive to: } & \multirow{2}{*}{$\begin{array}{c}\text { Patch Test Negative } \\
\text { to All Agents }\end{array}$} \\
\cline { 3 - 5 } & & Potassium Dichromate & Other Agents & \\
\hline $\begin{array}{l}\text { Assembling } \\
\text { All other jobs }\end{array}$ & 130 & $\begin{array}{c}47(36 \%) \\
9(9 \%)\end{array}$ & $11(8 \%)$ & $72(46 \%)$ \\
\hline
\end{tabular}

$\chi^{2}=21.9 ; P<0.001$

Forty-seven of the 56 men sensitized to dichromate were assemblers. Only nine cases of chromate sensitivity were found among the 100 men in all the other jobs. This gives a rate of chromate sensitivity in assemblers four times greater than in the rest of the factory (Table 6). Sensitivity to the other reagents is more evenly distributed and shows no occupational bias; there were 11 positive reactions among the assemblers and 15 in the rest of the factory.

Exposure to Chromates.-Assembly operations consist of fixing parts together with nuts, bolts, screws, and washers. Usually the parts are handled, and the operator collects the day's supply himself. It had been noted in the main assembly building that many of the rashes among the assemblers affected the first finger and the thumb. Some of these men were sensitive to patch tests with potassium dichromate. Testing of some of the hardware, as it is called, for chromate was begun about the time that the present work was started. No word of this had reached the engine assembly department, but the foreman had observed that men using the hardware were particularly prone to skin disease, and he thought it was due to friction from the screws. As the evidence of chromate sensitivity began to accumulate, the laboratories which serve the engine assembly department were also asked to test samples of the nuts, bolts, screws, and washers for chromate. The diphenyl carbazide test was used $\dagger$. In the assembly building six out of 15 samples tested showed signs of a yellow residue on the surface and gave a positive reaction for water-soluble chromates. In the engine assembly department 11 out of 34 samples tested were positive. There is much mobility of labour in all assembly lines, and with approximately one third of the hardware showing traces of chromate, any man on these lines may have had contact with chromate. It is normal engineering practice to treat steel parts that have been freshly zinc-plated with a chromate dip. This process, known as "passivation", helps the parts to resist

†xtraction of the part in hot water is followed by acidification of the solution with dilute hydrochloric acid and addition of $1 \%$ alcoholic solution of diphenyl carbazide. Development of a persistent red colour is specific for hexavalent chromium salts and is sensitive down to 10 p.p.m. oxidation and other atmospheric erosion. Passivation is effected by the absorption on the surface of the zinc of the chromate radicle, which then becomes insoluble in cold water and allows subsequent rinsing of the part. Inadequate rinsing could result in additional chromate being retained on the surface, increasing any hazards associated with the handling of chromated parts.

The results of this investigation, stressing the high incidence of chromate sensitivity among assemblers, the importance of chromate sensitivity as a cause of industrial dermatitis, together with the finding of a source of chromate in the nuts, bolts, screws, and washers, were presented to the management of the organization. It was decided to treat the engine assembly department as the subject of a pilot experiment and to eliminate chromate from all nuts, bolts, screws, and washers in that department.

Instructions were given to the plating and phosphate coating shop, which supplies the engine assembly department, to omit the chromate dip from the process. Furthermore, hardware from outside suppliers was to be bought as bare steel and plated and phosphated in the same shop, also without the use of a chromate dip.

A year after the first survey in the engine assembly department, and six months after the withdrawal of the chromate dip, a further survey of the department was undertaken. The prevalence of dermatitis had fallen from $12.2 \%$ to $6.5 \%$, a decrease of $47 \%$. Twelve new patients suffering from dermatitis were discovered. These patients were tested with the same series of sensitizing substances. None had a positive reaction to potassium dichromate. It is concluded that the hazard to the skin from hexavalent chromates has been eliminated from this department.

\section{Discussion}

Multiple Sensitivity.-There was some difficulty in interpreting the results of the patch tests with more than one positive reaction. The two patients who had four positive reactions were re-tested after six weeks but the same results were obtained. Baer (1954) discusses the significance of multiple sensitivities and gives three causes. First, multiple reactions 
may be due to unrelated coincidental sensitizations. The patient who was sensitive to colophony and paraphenylene diamine and who suffered an acute but short episode of dermatitis of the face while his wife was using a hair dye, but had an eczematous condition of the hands which preceded and continued after the episode, falls into this group. Secondly, there is cross-sensitization due to chemically related substances. Some of the patients in the series had a very long history of skin disease and may have been treated with topical applications of sulphonamide or other sensitizers, and reactions, particularly to paraphenylene diamine, may be due to chemical relations with substances which are not included in the test substances. Thirdly, Baer describes non-specific or false positive reactions due to an excessive reaction of the skin in an already eczematous subject.

Sensitivity to Agents other than Chromates.Fourteen men gave a positive reaction to colophony resin. This is a constituent of most medical plasters, and the adhesive tape widely used in packaging and the electricians' insulating tape are possible industrial contacts.

There were seven positive reactions to turpentine. Two of the men worked in the paint shop, and one was a French polisher at home. Most of the men do their own home decorating. The contact may have been with paints containing turpentine or with turpentine used as a thinner or in polishes. Medically, turpentine is used in embrocations and lotions.

The sensitivity to nickel, balsam of Peru, and the rubber additives probably arose from non-industrial contacts. Two of the men sensitive to nickel had patches of eczema on the wrist, and their wrist watches may have been responsible. Hjörth (1959) found that sensitivity to balsam of Peru was as common as nickel sensitivity; four positive reactions were obtained in this series. It is used as a fixative in hair creams, sprays, and perfumed soap and in several makes of vaseline gauze dressings; also there is a cross sensitivity to benzoin and balsam of Tolu. The rubber additives (MBT and MS) are extremely widely used. One of the six patients with positive reactions admitted to mending his children's shoes.

Chromate Sensitivity.-Allergy to hexavalent chromate is one of the commonest causes of contact dermatitis. In Wagner's (1959) series of 500 cases of allergic contact eczema, it was responsible for $34 \%$ of the cases. Chromate dermatitis occurs most frequently in the building trade. The association between cement dermatitis and sensitivity to chromate was pointed out by Jaeger and Pelloni (1950), who reported that $94 \%$ of 32 patients with cement dermatitis were positive to patch tests with potassium dichromate and found samples of cement contained minute quantities of chromium. Johnston and Calnan (1958) also found 17 out of 24 samples of cement contained chromate, and Anderson (1960) tested 66 patients with cement dermatitis, of whom $63 \mathrm{had}$ patch tests positive to potassium dichromate.

Walsh (1953) considers dermatitis is the most important of the chromate hazards encountered in industry. He reviews the uses of chromates and mentions processes which have given rise to industrial dermatitis. As well as chromium plating there is the anodizing of aluminium parts in the aircraft industry, the zinc chromate used as a primer paint investigated by Hall (1944), and chromate solutions used in the tanning of leather, wood preservation, photo-engraving, and dyeing. Hexavalent chromate is also a powerful anti-rust agent and is unusual in being the only additive to inhibit oxidation in all cast irons and zinc (Hersch, Hare, Robertson, and Sutherland, 1961).

Winston and Walsh (1951) describe six severe cases of chromate dermatitis among 200 diesel locomotive workers. They were using an anti-corrosive radiator fluid with a concentration of $6 \%$ sodium bichromate. The final concentration in the radiator was $0.08 \%$, draining and filling was awkward, and soiling of the men with fluid from the radiators was common.

Sensitivity to chromate from handling "passivated" steel parts has not been previously described and may well be an important source of dermatitis in the engineering industry.

This investigation could not have been made without the co-operation of the management and workers of the Ford Motor Company at Dagenham, and the assistance of the medical and nursing staff. My thanks are particularly due to Dr. H. O. Engel and Dr. J. T. Allardyce. Grateful acknowledgement is also made to Professor C. D. Calnan and Professor R. S. F. Schilling for their help and advice.

\section{REFERENCES}

Anderson, F. E. (1960). Brit. J. Derm., 72, 108.
Baer, R. L. (1954) In Modern Trends in Dermatology (2nd series), ed. R. M. B. MacKenna, p. 232. Butterworth, London

Calnan, C. D., and Engel, H. O. (1963). Brit. J. industr. Med., 20, 192. Hall, A. F. (1944). J. Amer. med. Ass., 125, 179.

Hersch, P., Hare, J. B., Robertson, A., and Sutherland, S. M. (1961) J. appl. Chem., 11, 251.

Hjörth, N. (1959). Trans. St. John's Hosp. derm. Soc. (Lond.), 43, 41 Jaeger, H., and Pelloni, E. (1950). Dermatologica (Basel), 100, 207.

Johnston, A. J. M., and Calnan C. D. (1958). Trans. St. John's Hosp. derm. Soc. (Lond.), (39th Report) 41, 11.

Pirilä, V. (1947). Acta derm.-venereol. (Stockh.), 27, Suppl. 16.

Wagner, G. (1959). Berufsdermatosen, 7, 307.

Walsh, E. N. (1953). J. Amer. med. Ass., 153, 1305.

Winston, J. R., and Walsh, E. N. (1951). Ibid., 147, 1133. 